\title{
Mídias e Educação Infantil: desafios na prática pedagógica
}

\section{Media and Early Childhood: challenges in the pedagogic practice}

\begin{abstract}
Resumo: Este texto tem o objetivo de conhecer o trabalho que professoras da educação infantil vêm realizando com as mídias massivas e digitais na sala de aula. Para tanto, adoto a perspectiva teórica dos Estudos Culturais latino-americanos, além das contribuições de autores como Lucia Santaella e André Lemos, para entender a relação dos sujeitos com essas mídias. A análise dos dados aqui apresentada baseia-se nas entrevistas semiestruturadas realizadas com sete professores que atuam na educação infantil. Os relatos dos sujeitos entrevistados apontaram que as práticas pedagógicas mediadas pelos artefatos tecnológicos atraem mais a atenção das crianças, e um dos desafios levantados a serem enfrentados é a maior promoção entre a cultura escolar e as práticas culturais das crianças com as mídias. Palavras-chave: Mídias. Prática Pedagógica. Educação Infantil.
\end{abstract}

Abstract: This text has the objective to be acquainted with the work that early childhood teachers are doing with massive and digital media in the classroom. To do so, I adopt the theoretical perspective of the Latin American Cultural Studies, and the contributions of authors such as Lucia Santaella and André Lemos, to understand the relation with the subjects with these media. The analysis of the data presented is based on semi-structured interviews carried out with seven early childhood teachers. The reports of the interviewed subjects showed that the pedagogic practices mediated by the technological artifacts attract more the attention of the children, and one of the raised challenges to be faced is the promotion between the school culture and the cultural practices of the children with the media. Keywords: Media. Pedagogic Practice. Early Childhood.

COUTO JUNIOR, Dilton Ribeiro. Mídias e Educação Infantil: desafios na prática pedagógica. Informática na Educação: teoria e prática, Porto Alegre, v. 16, n. 2, p. 131-146, jul./ dez. 2013.

\section{Dilton Ribeiro do Couto Junior \\ Universidade do Estado do Rio de Janeiro}

\section{Introdução}

V inculado ao projeto institucional "Educação e processos comunicacionais pósmassivos: implicações para práticas educativas em espaços formais e não-formais de educação" ${ }^{\prime \prime}$, este texto propõe conhecer o trabalho que professoras da educação infantil vem realizando com as mídias massivas e digitais na sala de aula. Parece importante que nos debrucemos sobre a necessidade de (re) pensar o papel da escola numa sociedade onde as produções culturais são cada vez mais presentes no cenário cotidiano pelo advento do avanço tecnológico. Santaella (2002) reconhece que "as mídias tendem a se engendrar como redes que se interligam e nas quais cada mídia particular - livro, jornal, TV, rádio, revista etc. - tem uma função que lhe é específica" (p. 49) e, portanto, seria interessante que as experiências dos sujeitos com os diferentes meios

${ }^{1}$ Coordenado pela professora Dra. Maria Luiza Magalhães Bastos Oswald no Programa de Pós-Graduação em Educação da Universidade do Estado do Rio de Janeiro (ProPEd/UERJ). 
midiáticos fossem compartilhadas, sendo reconhecidas e vivenciadas também na escola.

As diversas mídias vêm possibilitando que a informação e o entretenimento sejam constantemente apresentados às pessoas de forma dinâmica e diversa. Imagens, textos, música, filmes, programas televisivos, shows musicais, jogos eletrônicos e sites da internet, por exemplo, têm uma riqueza de linguagens que poderiam ser exploradas na sala de aula. Entretanto, Nóvoa (1999) ressalta que os processos de ensino-aprendizagem ainda supervalorizam os conhecimentos das grades curriculares e que muitas vezes não dialogam com as práticas sociais dos educandos. Caberia, então, perguntar se não seria válido, diante das práticas sociais mediadas pelas tecnologias, buscar metodologias de ensino que superem a perspectiva em que o conhecimento é trabalhado linear, gradativa e individualmente.

Considerando que, para Nóvoa (1999), "é fundamental encontrar espaços de debates, de planificação e de análise, que acentuem a troca e a colaboração entre os professores" (p. 16), a entrada das diferentes mídias no campo educacional também poderia instigar o surgimento de reflexões quando se pretende conhecer e dar visibilidade ao trabalho que os professores realizam com as tecnologias na sala de aula, dos produtos massivos aos digitais. Mostrando preocupação com o papel do professor e dos estudantes frente às tecnologias, Lévy (1999) faz o seguinte comentário:

Não se trata aqui de usar as tecnologias a qualquer custo, mas sim de acompanhar consciente e deliberadamente uma mudança de civilização que questiona profundamente as formas institucionais, as mentalidades e a cultura dos sistemas educacionais tradicionais e sobretudo os papéis de professor e de aluno (p. 172, grifos do autor).
Orofino (on-line) aponta a necessidade de que sejam criadas práticas educativas "por meio de novos enfoques pedagógicos que visem um consumo cultural crítico e que possibilitem a criação de estratégias de uso destes meios para fins emancipatórios e libertadores" (grifos da autora). Ao adotar as contribuições teóricas de autores que integram os Estudos Culturais latino-americanos, como Jesús Martín-Barbero e Néstor García Canclini, a autora apresenta uma ótica que compreende a reapropriação do consumo cultural pelas audiências ao interagirem com os produtos. Isso significa reconhecer os usos e apropriações que as audiências fazem dos diferentes meios de massa, como a televisão, o rádio, o cinema. Assim, negar que o público infantil se aproprie criticamente dos mesmos é não "levar em consideração o fato de que as crianças vivem, crescem, brincam e apreendem o mundo em sua volta de maneiras muito diversificadas" (OROFINO, 2005, p. 43).

No presente trabalho, a criança é compreenda segundo Leite (2007), "como ser social situado no tempo e no espaço, como cidadã hoje, que tem suas especificidades em relação aos adultos" (p. 74). Concordo com Jobim e Souza (2007a), quando diz que a criança é um sujeito na/da história. Entretanto, muitas vezes a criança é vista como estando desvinculada de seu contexto sociocultural, e essa dimensão adultocêntrica de compreendê-la inviabiliza "o verdadeiro diálogo com ela, ou seja, aquele diálogo em que ela nos mostra os espaços sociais e culturais de onde emergem a sua voz e o seu desejo" (p. 45). Para Leite (2007), seria fundamental estreitar as relações entre alunos e professores e entre a escola e a vida. Para isso, a autora reconhece o aluno "como sujeito capaz de agir sobre sua trajetória; como narrador, produtor e consumidor de cultura que, através da e na linguagem, impri- 
me suas marcas, reelabora o seu passado, vive o seu presente e tem possibilidade de não aprisionar o seu futuro" (p. 87). Diante disso, faz-se imprescindível entender os diversos pontos de vista da criança, reconhecendo seus papéis de agentes sociais, de consumidores e produtores de cultura, partilhando experiências que nos permitam considerá-las como aquelas que têm muito a nos ensinar, conferindo-nos a esperança de contribuir para que a prática pedagógica leve em consideração o desejo e o interesse delas pelas diversas mídias².

\section{Procedimentos teórico-metodoló- gicos}

A análise dos dados apresentada neste texto baseia-se nas entrevistas semiestruturadas realizadas com sete professoras que atuam na educação infantil, em diferentes escolas privadas do Rio de Janeiro, com turmas que abrangem a faixa etária dos 3 aos 5 anos. Vale ressaltar que utilizei nomes fictícios para me referir às educadoras, preservando, desta forma, a identidade das entrevistadas e das escolas em que trabalham. A relação com os sujeitos da pesquisa se deu na perspectiva das investigações que os tomam como parceiros da tarefa de conhecer o que ainda é desconhecido. Para tanto, busquei ajuda em Canclini (2005), para quem a pesquisa "remete à confrontação e ao entrelaçamento, àquilo que sucede quando os grupos entram em relações e trocas" (p. 17), o que implica na compreensão

\footnotetext{
${ }^{2}$ Ainda que a pesquisa tenha discutido os usos das mídias de massa com as professoras de educação infantil, uma vez que são popular e amplamente incorporadas nas atividades de sala de aula, a principal ênfase do trabalho foi um olhar mais atento acerca das mídias que veiculam imagens em movimento. Estas últimas, cada vez mais presentes no cotidiano de crianças e adultos, vêm oportunizando aos educadores inúmeras reflexões na construção e desenvolvimento de atividades mediadas pela linguagem audiovisual com as crianças na escola.
}

de que, segundo o autor, "os diferentes são o que são, em relações de negociação, conflito e empréstimos recíprocos" (p. 17). Jobim e Souza (2007b), acerca das pesquisas que fazem uso de entrevistas com os sujeitos, diz que quando se estabelece um dialogo entre pesquisador e pesquisado, a troca de experiências pessoais é imprescindível para contribuir com a produção de conhecimento, que deve ser compartilhado para ser construído. O conteúdo das entrevistas, interpretado à luz do referencial teórico-metodológico adotado, propiciou o desenvolvimento das reflexões tecidas no presente trabalho de pesquisa.

Além disso, adotei como cenário de realização de quatro entrevistas o Windows Messenger, popularmente conhecido como MSN. A opção por este ambiente digital deve-se ao fato do que Lemos (2002) afirma sobre as possibilidades de ampliação do fluxo da informação a partir do uso da tecnologia. O MSN pode ser considerado como mais uma possibilidade de promover o diálogo com os sujeitos, ainda mais quando a ênfase das discussões durante as entrevistas giraram em torno da relação estabelecida pelas professoras com as tecnologias, e como essas últimas são incorporadas nas práticas educativas na escola. As entrevistas realizadas à distância certamente proporcionaram que eu pudesse "usar a tecnologia para construir estratégias de interação com o mundo físico e social, que sejam promotoras de um certo modo de ver as coisas, interpretando e recriando o mundo de muitas e diferentes maneiras" (JOBIM; SOUZA, 2002, p. 77). 


\section{3 "[...] é uma coisa que chama mui- to a atenção deles, muito mesmo": o vídeo na sala de aula}

Constituindo-se como mídia de massa, o que implica na impossibilidade das audiências interferirem sobre o polo da emissão, ainda existem muitos estudos que se dedicam a investigar a televisão sob uma ótica que a compreende como responsável por tornar "os telespectadores idiotas (então idiotizam-se miIhões e milhões de brasileiros diariamente, o que torna o seu estudo ainda mais premente)" (BACCEGA, 2003, p. 59). Longe de concordar com esta perspectiva de análise, os sujeitos são aqui identificados conforme a linha teórica dos Estudos Culturais latino-americanos: "como protagonistas ativos que se manifestam politicamente por intermédio de práticas e ações culturais que correspondem ao seu tempo" (MARTINS; COUTO JUNIOR, 2007, p. 2), reconhecendo que fazem uso dos meios midiáticos como possibilidades de reapropriarem-se de seu conteúdo. Orofino (on-line), sobre essa perspectiva teórica, acredita no "importante papel que os meios de comunicação desempenham na constituição das dinâmicas culturais contemporâneas".

Seja para a exibição de filmes em DVD ou de programas televisivos, práticas comuns no cotidiano escolar das professoras entrevistadas, a televisão tem atraído a atenção das crianças da educação infantil. Marta comenta que o entusiasmo de seus alunos de 3 anos pelos filmes em DVD tem feito com que os mesmos se desinteressem pelas atividades em sala que não fazem uso das diferentes mídias: "eu percebo que o DVD é uma coisa que é mais forte, não é, em relação a eles... eles ficam assim... hipnotizados com o DVD, é uma coisa que cha- ma muito a atenção deles, muito mesmo. Então é um meio de, é um meio de comunicação que é difícil duelar, sabe?". A fala da professora expressa sua preocupação de desenvolver um trabalho com o uso dos diversos meios midiáticos na tentativa de tornar a prática pedagógica mais prazerosa para seus alunos, ao mesmo tempo em que há atividades onde estes artefatos não são utilizados, criando-se a dificuldade, segundo ela mesma relata, de cativar as crianças no aprendizado de novos conhecimentos. Marta reconhece que as atividades propostas por ela sem o uso das mídias precisariam ser ressignificadas, pois como ela mesma reforça, cria-se uma espécie de "duelo" entre os processos educacionais mediados pelas diversas tecnologias e os processos em que estas não são incorporadas. A professora ressalta, inclusive, que ainda há falta de sintonia entre o que as crianças gostariam de encontrar na escola e o que a escola é capaz de oferecer a elas. Concordo com Leite (2007), quando afirma ser

fundamental que haja circulação de conhecimento, que se permeie o acesso ao mundo letrado, às ciências de modo geral; esses conhecimentos precisam ser reapropriados por todos, de forma a se criar um vínculo entre esse conhecimento formal e a vida. Vida - é o que falta na escola! (p. 85).

Dentro desse panorama, como os processos educacionais poderiam se aproximar da vida das crianças? O que deveria ser levado em consideração para a construção de metodologias de ensino que dialoguem com os desejos e os interesses das crianças? Como as diversas mídias poderiam auxiliar professores na criação de vínculos mais estreitos entre o conhecimento formal da escola e a vida das crianças?

Segundo a professora Natasha, é evidente o interesse dos seus alunos de 4 anos pelas 
imagens em movimento, que os motiva mais do que a música: "o rádio meio que dispersa eles. Assim, eles estão escutando a musiquinha tal, estão cantando, mas daqui a pouco estão fazendo outra coisa e já esqueceram que o som está ali. Coisas que eles estão vendo, assim, eles ficam mais presos". Isso remete para o que Jobim e Souza (2002) ressalta a respeito do olhar mediado pela tecnologia. De acordo com ela "as imagens constituem hoje as narrativas do mundo contemporâneo, trazendo novos elementos para buscarmos uma compreensão mais abrangente do próprio conceito de narrativa" (p. 79). Neste sentido, sem desconsiderar a importância indiscutível da relação das crianças com a música, é preciso reconhecer que vivemos nitidamente marcados pela forte presença da imagem na sociedade contemporânea, que vem reconfigurando as práticas sociais. Não se trata de supervalorizar determinadas mídias em detrimento de outras, mas de "destacar a importância que as indústrias da mídia e os múltiplos e contraditórios conteúdos por elas veiculados desempenham nos processos de constituição de identidades individuais e coletivas" (OROFINO, on-line). Para isso, há de se promover na escola novas formas de se relacionar com a tecnologia, com a possibilidade, segundo Jobim e Souza (2002), de também tornar "as imagens técnicas mediadoras de um diálogo entre pessoas que buscam novos modos de narrar sua experiência, recriando o mundo na imagem e no discurso" (p. 80).

A partir dessa perspectiva para pensar a produção do conhecimento com os usos das mídias na prática pedagógica, seria preciso levar em consideração o modo pelo qual as crianças compartilham gostos, crenças e ideias, produzindo sentidos diversos pela necessidade de se relacionarem com o conhecimento e a cultura a partir da relação que estabelecem com as imagens em movimento na sala de aula. Jobim e Souza e Kramer (2003) ressaltam que crianças e professores "são sujeitos históricos. São produtores de linguagem. Linguagem que os constitui como sujeitos humanos e sociais sempre imersos em uma coletividade" (p. 15). Assim, a participação coletiva dos sujeitos em sala de aula faz-se imprescindível para que os processos de ensino-aprendizagem mediados pelas mídias contemporâneas ofereçam a todos a oportunidade de se manifestarem culturalmente e promoverem o intercâmbio de experiências.

Embora a imagem digital desenvolva um papel bastante privilegiado na vida cotidiana de educadores e educandos, Carla revelou que existem momentos na sua escola em que os filmes em DVD a serem exibidos acabam resultando numa atividade que não propicia momentos de diversão para as crianças. De acordo com a professora, muitos de seus colegas na instituição exibem filmes sem apresentar critérios que justifiquem a sua importância, bem como não envolve a participação das crianças na escolha da produção cinematográfica. De acordo com Carla, o uso da sala de vídeo da instituição onde trabalha é vista pela maioria dos professores como um "momento de descanso" para as professoras, que colocam as crianças a assistirem um DVD. A partir daí, será que o DVD, por si só, garantiria as necessárias mediações para que processos de ensino-aprendizagem ocorram? Carla certamente acredita no papel mediador do professor para criar formas interessantes e criativas de uso das tecnologias, instigando suas crianças pequenas a entrar em contato com outros conhecimentos, favorecendo a troca de experiências dentro da sala de aula. Nesse sentido, a seguinte pergunta formulada por Jobim e Souza (2002) é pertinente: "quais são as possibilidades de criação e de liberdade em uma 
sociedade cada vez mais programada pela tecnologia?" (p. 75). Descontente em como a sala de vídeo vem sendo utilizada em sua escola, a professora ressalta: "então muitas vezes nossos próprios colegas de trabalho passam filmes longos demais, os quais deixam as crianças entediadas". Isso não deixa dúvida que ainda é preciso a promoção de inúmeras reflexões sobre os usos da linguagem audiovisual no trabaIho com as crianças, principalmente com a popularização das tecnologias digitais, que vêm mediando novos modos de ensinar e aprender, ressignificando a forma como a informação é apresentada e produzida pelos sujeitos.

A professora Luciana acredita que deve haver certos cuidados no que diz respeito às atividades que fazem o uso dos meios midiáticos: "a gente usa esse recurso quando tem a ver com o nosso projeto. Quando é a criança que traz o DVD de casa ou pede muito para assistir, a gente abre este espaço para a criança estar dividindo isso com os seus amigos. Você vê que aquilo é importante para ela". Percebe-se, portanto, o quanto a intervenção do professor é essencial ao desenvolvimento de metodologias que promovam uma relação prazerosa, crítica e criativa com a imagem na sala de aula. Segundo Orofino (2005), "as mediações não estão dadas" (p. 51), mas se constituem como parte da prática pedagógica no sentido de ensejar ações que favoreçam as reapropriações por parte das crianças no contato com as diversas produções da indústria cultural.

Acredito o quanto seria importante reconhecer a criança como um sujeito que apresenta interesses e desejos, e que poderiam ser incorporados no planejamento das atividades pedagógicas, oportunizando momentos de aprendizagem a partir da relação de troca entre os pares. Para Carvalho (1997),
É fundamental que se perceba a criança como um sujeito que pensa, age, pertence a uma classe social, está inserido em um contexto, que constrói e se constrói na cultura, que produz e é produtor de linguagem, ou seja, a criança é um ser social, histórico, político e cultural. E isso é fato. E é por essa criança que se deve lutar. Não para que ela seja o adulto de amanhã, e sim, porque ela é um sujeito hoje (p. 122-123).

$\mathrm{Na}$ entrevista com as professoras Raquel e Natasha, as educadoras mostraram-se bastante preocupadas em repensar constantemente a prática pedagógica em suas turmas com crianças de 4 anos, apontando que as atividades propostas, mediadas ou não pelo uso de suportes tecnológicos, devem estar associadas a um contexto que apresente significado para os alunos. No trecho da entrevista a seguir, Raquel critica o fato de que, devido à inexistência de recursos tecnológicos na sua sala de aula, as atividades centralizam-se basicamente nas folhas de papel, com a forte presença de atividades voltadas para a prática do desenho.

Raquel: É uma ligação maior mais próxima deles com a máquina. E dentro da sala de aula não tem isso. Pelo menos na minha sala de aula não tem. É só no papel, só no papelzinho, então a atenção deles dispersa mais. Eu coloco um DVD, [...] porque é uma ligação muito forte, porque eles gostam.

Pesquisador: Pintar não pode ser prazeroso?

Raquel: É, mas só isso, o tempo todo, todo dia, de segunda a sexta, não é. Essa é a questão, não é?

Natasha: Eu acho que também pintar é prazeroso, mas o que você está pintando... depende, assim, do que você está pintando...

Na conversa com Raquel e Natasha, não pude deixar de perceber que muitas vezes são os próprios professores que reconhecem 
o desprazer das crianças ao realizar atividades em sala de aula. Sobre isso, Nogueira (2007) levanta inúmeras reflexões ao afirmar que as atividades escolares podem desencadear o desinteresse das crianças, até mesmo quando o computador media os processos de ensinar e aprender:

o prazer transforma-se, algumas vezes, em desprazer, em irritação: com a professora que corrige um erro, sem perceber o processo da criança; com companheiro de um grupo que não ajuda na composição de um trabalho. Transforma-se em frustração e desinteresse [também] quando o uso do computador passa a ser imposto, excessivamente dirigido. $\mathrm{O}$ computador, objeto de prazer em casa, entra na escola, muitas vezes, transfigurando em trabalho-obrigação, perde seu encanto, seu mistério. Por que a escola não aproveita o interesse da criança pelo computador? Por que torna maçante o que é, em outros contextos, interessante? (p. 113).

Além disso, indo na mesma direção que Nogueira (2007), que outras atividades perderiam a magia e o mistério ao serem incorporadas nos processos educacionais?

Embora os artefatos tecnológicos muitas vezes não sejam possíveis de serem utilizados e incorporados nas práticas pedagógicas de muitas escolas, ainda assim isso não justifica que as crianças devam realizar atividades pouco interessantes, desvinculadas dos seus contextos. O desenho, por intermédio do suporte tradicional que é o papel, pode ser um caminho para expressar artisticamente a vivência delas na relação estabelecida com os meios tecnológicos contemporâneos. Algebaile (2007), numa pesquisa realizada com meninos e meninas de baixa renda de uma escola pública no Brasil, pode contribuir para pensar sobre a relação das crianças com os professores. A partir da seguinte pergunta, a autora levanta uma pista para se pensar sobre a prática pedagógica: "então, como chegar à criança? Um caminho se mostrou: o lúdico. Dobradura, música, literatura infantil, desenho, recorte e colagem, dramatização, mímica, confecção de marionetes, brinquedos e brincadeiras" (p. 129). O lúdico poderia se constituir como um caminho capaz de melhor compreender o ponto de vista da criança quando esta denuncia um espaço que tem se mostrado nada atraente para a realização de suas atividades diárias. Pensar ludicamente a mediação da linguagem audiovisual na escola poderia ser uma estratégia para criar nas crianças o desejo e a necessidade por novas experiências de ensino-aprendizagem.

Para Leite (2007), o lúdico muitas vezes encontra-se ausente da instituição escolar, "ausente da relação professor-aluno, da possibilidade de brincar, dançar, pintar, passear, mexer-se. É preciso que a escola compreenda a importância do lúdico na formação, não apenas da crianças mas também do educador" ( $p$. 81). Atividades como jogos de montar, jogos de mesa e os jogos cooperativos também se constituem como outras possibilidades, além do uso do vídeo, para serem incorporadas na escola, considerando a ludicidade como aspecto fundamental no trabalho com crianças. Além das brincadeiras e dos jogos tradicionais infantis, a linguagem audiovisual também apresenta especificidades importantes no trabalho com as crianças, além do estreitamento dos laços entre professor-alunos. Sobre isso, Canclini (2005) revela que já é possível perceber a ocorrência de modificações na forma como os sujeitos se relacionam com a informação, o conhecimento e o entretenimento, ao ressaltar que "a conjugação de telas de televisão, computadores e videogames está familiarizando as novas gerações com os modos digitais de experimentar o mundo, com os estilos e ritmos de inovação próprios destas redes" (p. 237). 
De acordo com o diálogo a seguir com a professora Carla, foi possível compreender que o contato de seus alunos de 5 anos com os programas televisivos em casa os têm levado a ressignificarem a forma como se apropriam deste conteúdo midiático na sala de aula, em atividades não mediadas pelo uso dos aparatos tecnológicos digitais:

Carla: Eu sei que eles veem novelas, que dormem tarde por estarem vendo televisão.

Pesquisador: E isso aparece bastante na sala de aula?

Carla: Eles fazem comentário do que aconteceu na novela, utilizam as falas de alguns personagens.

Pesquisador: E muitos compartilham desse mesmo interesse?

Carla: Na brincadeira de massinha, as meninas colocam aqueles apetrechos do [programa da novela] "Caminhos das Índias"3. $\mathrm{O}$ assunto surge quando estão fazendo trabalhos.

Considerando que, para Baccega (2003), "a televisão tornou-se, no Brasil, o espaço de reconhecimento da própria identidade nacional" (p. 57), a sua utilização no espaço escolar justifica-se como mais do que necessária. As muitas referências que as crianças fazem ao conteúdo televisivo no cotidiano escolar apontam para a ideia de que este artefato cultural desempenha grande interesse no público infantil, e vêm propiciando que os professores percebam os sentidos produzidos por seus alunos na relação que estabelecem com a referida mídia. Desta forma, as atividades escolares desenvolvidas com o uso da televisão permitem abrir caminhos para uma reflexão de como outros meios midiáticos tam-

\footnotetext{
${ }^{3}$ Escrita por Glória Perez, "Caminho das Índias" foi uma telenovela brasileira exibida em 2009 pela Rede Globo. Ganhou o Emmy Internacional 2009 na categoria de melhor telenovela. Informações disponíveis em: http://pt. wikipedia.org/wiki/Caminho das \%C3\%8Dndias. Acesso em: 20 set. 2012.
}

bém poderiam ser incorporados nas práticas pedagógicas. Há muitos recursos tecnológicos à disposição dos professores atualmente, possibilitando que os conhecimentos sejam abordados em sala de aula de formas diferentes, como é o caso do computador, cada vez mais popular no cotidiano de professores e estudantes.

\section{4 "[...] a criança bota o dedo e vai arrastando as coisas": o computa- dor na sala de aula}

Mais recentemente, autores como Lucia Santaella e André Lemos, do campo da comunicação, têm trazido contribuições que auxiliam a pensar a relação dos sujeitos com as mídias digitais, que permitem aos mesmos romper com o polo da emissão pela "possibilidade de acesso, produção e circulação de informação em tempo real" (LEMOS, on-line, p. 12). Se em relação aos produtos da cultura de massa o telespectador que assiste à televisão ou ouve o rádio não pode interferir no conteúdo transmitido, no caso dos produtos da cultura digital, o sujeito já não é um mero telespectador.

A exploração da internet no cotidiano da educação infantil parece desejável, na medida em que, segundo Machado (2004), a mídia eletrônica é "reconhecida como campo de possibilidades para a expressão estética" ( $p$. 7). Para Santaella (2004), é o usuário que traça o seu próprio roteiro de navegação a partir do que the é apresentado na tela, interagindo em meio a vídeos, imagens, textos, sons e gráficos. A cultura digital, que engloba as experiências propiciadas pelos usos dos computadores, possibilita aos usuários navegar de formas muito diversas nos ambientes digitais da internet, sendo esta uma "uma espécie de 
céu aberto para uma multiplicidade de atividades interativas que não existiram no passado. Particularmente, a abertura congênita das redes $[\ldots]$ permite que uma pletora de vozes sejam ouvidas pelo mundo por um custo mínimo" (SANTAELLA, 2002, p. 55), e isso vem provocando transformações nos processos comunicacionais e reconfigurando as relações sociais.

A professora Natasha revela que durante as idas de sua turma ao laboratório de informática, ela percebe uma mudança de comportamento no que diz respeito ao entusiasmo das crianças de 4 anos: "parece outra criança. Parece, assim, todo mundo hipnotizado. Você chama e nem te olha. Parece que aquilo ali é, é a melhor coisa do mundo. Eles ficam, eles jogam. Aí tem... e é aquilo que eu falei, quanto mais difícil, mais eles gostam, não é?". Diante disso, Machado (2002) argumenta que as imagens geradas pelo computador, cada vez mais frequentes no cotidiano das pessoas, faz com que os sujeitos vivenciem a experiência de mergulhar nos ambientes virtuais por meio da sensação de imersão. Ferreira e Couto Junior (2009), com base em entrevistas realizadas com gamers, ressaltam que "a sensação de imersão e o caráter interativo proporcionado pelas mídias digitais contribuem significativamente para a constituição de subjetividade desses sujeitos, instaurando novos modos de relacionar-se com a informação e o conhecimento" (p. 89).

Os games são muitas vezes utilizados nos computadores do laboratório de informática, conforme mencionado por algumas professoras entrevistadas, sendo que uma delas, Luciana, também teve a experiência de participar, quando criança, de partidas de vídeo-games com sua irmã mais velha. De acordo com ela, várias foram as sensações vivenciadas devido ao envolvimento emocional com a trama digi- tal: "você começa a ficar estressado. Eu já me vi estressada jogando vídeo-game. Quando eu jogo eu levo aquilo, porque você se estressa até passar, é uma coisa de você com você mesma. Você quer vencer, você sabe que você é capaz". Isso aponta para o que Santaella (on-line) diz ser proveniente do vínculo estabelecido entre o jogador e o personagem digital do mundo fictício, uma vez que é a "identificação encarnada que se responsabiliza pela intensificação da competitividade e pelo envolvimento emocional e afetivo do interator". Além disso, os cenários digitais dos jogos eletrônicos "atuam muitas vezes como espaços de catarse, nos quais é possível expressar medos, afetos, angústias sem correr o risco de ser pré-julgado, vivenciando situações que não podem se concretizar no dia-a-dia" (ALVES, 2006, p. 216).

Diante disso, parece interessante reiterar a necessidade de promover os usos das mídias digitais na sala de aula, uma vez que há, para Alves (2006), a ocorrência de transformações nas percepções dos usuários ao navegar nos espaços virtuais da internet ou dos jogos eletrônicos. Segundo a autora, estes são ambientes que caracterizam-se "por formas de pensamento não-lineares, que envolvem negociações, abrem caminhos para diferentes estilos cognitivos e emocionais" (p. 216). Marta defende as possibilidades de usos dos jogos eletrônicos na escola como meio de promover o ato criativo com essa mídia na educação infantil: "você vai errar também, você vai ser o mal, você vai ser o bem, você vai viver a fantasia ali naquele jogo, que é uma fantasia". Durante as atividades no laboratório de informática, Natasha também comenta que o jogo ocupa lugar central para muitas de suas crianças de 4 anos, como ela mesma relata a respeito de uma em particular: "- ô professora, posso entrar no site, entrar no jogo do Power Rangers?". A professora faz questão de 
ressaltar que "ele sabe, ele sabe, ele entra. Ele liga o computador, ele entra na internet, ele escreve o nome do site".

No caso dos jogos com propósitos educacionais, Santaella (2012) ressalta que o maior desafio "é oferecer para o aprendiz um ambiente em que os usuários queiram estar, queiram explorar e fiquem entretidos em tal intensidade que aprendem sem sentir que estão aprendendo" (p. 171). O aspecto lúdico dos jogos eletrônicos deve ser considerado na aprendizagem de diferentes conhecimentos. Se antes as aprendizagens vinham ocorrendo a partir de atividades como a "contação" de histórias e as brincadeiras de faz-de-conta, agora existem outras aprendizagens que emergem com as linguagens audiovisuais, despertando também a curiosidade das crianças.

$\mathrm{Na}$ imaginação infantil, o mundo do qual as crianças fazem parte é incorporado por elas de forma a ser recriado nas brincadeiras e jogos (eletrônicos ou não). Conforme afirma Brougère (2002), a ludicidade é incorporada nas brincadeiras e nos jogos tradicionais pela criança. Kishimoto (2002) aponta que os jogos e as brincadeiras proporcionam a colaboração entre as crianças, que vivenciam situações imaginárias no desenvolvimento, permitindo que o potencial criativo delas seja atingido. As regras são características marcantes de todas as brincadeiras e jogos, como é o caso do xadrez, da amarelinha e das brincadeiras de faz-de-conta. No caso dos jogos eletrônicos, as crianças tomam as decisões consideradas necessárias, têm a possibilidade de produzir hipóteses e expressar sentimentos, estimulando a imaginação e a criatividade quando interagem com os ambientes digitais a partir dos personagens da trama eletrônica. Leite (2007) ressalta que "o brincar não é uma característica infantil, mas do ser humano. A fantasia, a imaginação são fundamentais, mas não são específicas ou ex- clusivas da criança" (p. 81); fundamentais no sentido de que podem potencializar as aprendizagens, incorporando aspectos da cultura lúdica nos processos educacionais.

A professora Juliana apresenta um relato interessante sobre o uso do computador como possibilidade de que seus alunos sejam apresentados ao universo dos signos. De acordo com ela, os processos de leitura e escrita mediados pelas tecnologias digitais são capazes de promover uma ponte com os conhecimentos trabalhados em sala. Isto tornou possível que uma de suas alunas de 5 anos, que apresentava dificuldade em ler e escrever no impresso, pudesse estar desempenhando essa prática com maior facilidade no computador: "então eu tinha uma aluna que escrevia, por exemplo, B-O-N-E-C-A faltando letras. Quando eu pedia para ela ler o que havia escrito ela identificava e sorria. Então tive a ideia de tirar o lápis dela e pedir para escrever no computador". Para Juliana, a dificuldade concentrava-se no traçado das letras, o que pôde ser aprimorado com o tempo. Segundo a professora, ao final do ano letivo a aluna afirmou: "- Juliana, aqui é meIhor para escrever porque eu vou falando baixinho e devagar o que eu tenho para escrever e vou achando as letras". Não há dúvida de que, de acordo com Juliana, "para escrever no computador é necessário apertar letra por letra e, ao mesmo tempo, ela conseguia visualizar todo o alfabeto no teclado", permitindo que os signos pudessem ser ressignificados. Se antes estes eram trabalhados unicamente na sala de aula por meio dos livros e cadernos, passaram a ser utilizados também com o auxílio de outro suporte, o computador. Não se trata da tecnologia substituindo as práticas pedagógicas em sala de aula, mas de serem utilizadas como potencializadoras e mediadoras dessas práticas, propiciando outras formas de explorar os conhecimentos. Simões e Couto Junior (2010) 
dizem que "as mudanças que engendram o contato dos sujeitos com os conteúdos midiáticos no ciberespaço os vêm tornando praticantes dos processos de leitura e de escrita a partir das demandas sociais que emergem nesse contexto cultural" (p. 3).

Numa sociedade que apresenta como uma de suas características marcantes a cultura da imagem, é contraditório que as práticas escolares apenas insistam em basicamente privilegiar os "textos impressos que, normalmente, constituem a biblioteca escolar" (Oswald, 2007, p. 2), desvalorizando muitas vezes os interesses de seus alunos em relação aos processos de leitura e escrita que também encontram-se presentes em outros suportes midiáticos. Alves, Japiassu e Hetkowski (on-line) afirmam que "a co-laboração na/em Rede, sem dúvida, pode contribuir para a emancipação do sujeito engajando-o em um genuíno processo de construção autônoma de novos conhecimentos e saberes". Para a professora Raquel, "a escola está um pouco desatualizada, ela não está andando junto com a velocidade da informação. A escola parece que está atrasada nesse ponto e os professores também". Defendo que a construção de processos legítimos de ensino-aprendizagem mediados pelos usos das mídias digitais não é tarefa simples, necessitando de políticas de formação que confiram aos professores condições concretas para implementá-los. O uso das mídias digitais na produção e no compartilhamento de ideias e opiniões, produzidas interativa, colaborativa e dinamicamente pelas crianças também possibilita legitimar e reconhecer as possibilidades de ensinar e aprender em tempos de cibercultura.

Dardeau (2009), referindo-se à importância do papel mediador do professor na relação dos estudantes com o conhecimento e a cultura, ressalta que não se trata apenas de assumir a postura de usar os novos meios para estimular o interesse do estudante, levando-o simplesmente a imergir no universo disperso de informações produzidas pela rede mundial de computadores e tecnologias afins, mas de, junto com ele, buscar maneiras de compartilhar a cultura digital como experiência democrática, capaz de ampliar o acesso ao saber, à arte e à cultura.

\section{$5 \mathrm{Na}$ busca pelas palavras finais}

Seria preciso refletir sobre qual papel se coloca para a instituição escolar numa época em que as tecnologias provocam transformações para a percepção e atuação humanas. Neste sentido, parece não ser a opção mais favorável negar a entrada das diversas tecnologias no espaço escolar, uma vez que estas vêm se popularizando na vida cotidiana das crianças e dos professores. Reinventar as práticas pedagógicas parece ser cada vez mais necessário e defendo que um dos possíveis caminhos para isso seria o de descobrir as potencialidades das diversas mídias nos processos comunicacionais contemporâneos, que abarcam o desejo e a necessidade dos sujeitos de se sentirem como produtores de cultura. Afinal, quais seriam os desafios a serem pensados na prática pedagógica, para criar nas crianças o desejo e a necessidade da produção e emissão de novos saberes?

A ideia de que o uso de mídias na escola é dificultado pelo pouco manejo que as professoras têm destes meios, especialmente os digitais, vem reforçando que somente as novas gerações seriam capazes de utilizar com destreza os artefatos tecnológicos, colocando em xeque a capacidade docente em criar condições de utilizar câmeras fotográficas, celulares, computadores etc. Os achados da pes- 
quisa apontam que as professoras reconhecem que há diferenças na forma como elas e seus alunos manuseiam os artefatos culturais; entretanto, isso não pode impedir que as práticas pedagógicas deixem de ser potencializadas e tirem proveito de outros suportes que vêm desempenhando transformações na relação do homem com a cultura e o conhecimento. A partir daí, é pertinente questionar que outras experiências sociais também vêm sendo construídas no ciberespaço, e que utilizam suportes responsáveis por criar ambientes em rede como os blogs, fotoblogs, Orkut, Facebook, Twitter e tantos outros. Para isso, é necessário que os professores integrem-se a essas redes, construindo novos olhares atentos aos modos de pensar o ensino e a aprendizagem dentro das dinâmicas das interfaces digitais contemporâneas. De acordo com os sujeitos entrevistados, as crianças da educação infantil encontram-se motivadas pelos usos da tecnologia na sala de aula. Sendo assim, como a educação poderia continuar incorporando essas novas linguagens na prática pedagógica, reconhecendo as crianças como agentes sociais, consumidores e produtores de cultura? Isso não significa desvalorizar ou inutilizar determinados suportes que ainda são incorporados nas práticas pedagógicas, como o quadro-negro, o livro didático, o retroprojetor, dentre outros, mas promover novas formas de entrar em contato com os co- nhecimentos. Nogueira (2007), numa pesquisa que investigou a relação de crianças com a tecnologia, concluiu que

Cortando, colando, experimentando, brincando com as cores, com as letras, com as texturas, com os efeitos visuais, as crianças começam a dominar a técnica de transformação da imagem eletrônica. Começam a perceber o que há por trás das imagens que estão a sua volta, transformando-se em leitores mais críticos. Talvez essa seja a imagem da mudança (p. 129).

Ramal (on-line) afirma que existe hoje "um paradoxo: aquele a ser educado é o que melhor domina os instrumentos simbólicos do poder, o aparato de melhor prestígio: as tecnologias. O que ocorrerá na sala de aula? Parece-me que as parcerias e a aprendizagem em conjunto serão inevitáveis". Diante disso, talvez seja possível descobrir, junto às crianças, formas de utilizar as diversas linguagens das diversas tecnologias, permitindo que os professores rediscutam e reflitam sobre suas próprias práticas pedagógicas numa era marcada pela cultural digital. Essas preocupações certamente não permitem que nós, enquanto educadores, "fiquemos à janela vendo a banda passar" (SANTAELLA, 2013, p. 46), mas que estejamos implicados nos desafios que o tempo presente nos traz. 


\section{Referências}

ALGEBAILE, Maria Angélica Pampolha. Entrelaçamento de vozes infantis: uma pesquisa feita na escola pública. In: KRAMER, Sonia; LEITE, Maria Isabel (Orgs.). Infância: fios e desafios da pesquisa. São Paulo: Papirus, 2007, 9a Ed, p. 121-47.

ALVES, Lynn. Jogos eletrônicos - novos locus de aprendizagem. In: CHAGAS, Claudia Maria de Freitas; ROMÃO, José Eduardo Elias; LEAL, Sayonara (Orgs.). Classificação indicativa no Brasil: desafios e perspectivas. Brasília: Secretaria Nacional de Justiça, 2006, p. 215-28.

ALVES, Lynn; JAPIASSU, Ricardo; HETKOWSKI, Tânia Maria. Trabalho colaborativo na/em rede: entrelaçando trilhas. Disponível em: <http://www.comunidadesvirtuais.pro.br/colaborativo/01.htm>. Acesso em: 26 ago. 2009.

BACCEGA, Maria Aparecida. Televisão e escola: uma mediação possível? São Paulo: Senac, 2003. BROUGĖRE, Gilles. A Criança e a Cultura Lúdica. In: KISHIMOTO, Tizuko M. (Org.). o brincar e suas teorias. São Paulo: Pioneira, 2002.

CANCLINI, Néstor García. Diferentes, desiguais e desconectados: mapas da interculturalidade. Rio de Janeiro: UFRJ, 2005.

CARVALHO, Maria Cristina. Infância, leitura e escrita - entrando numa escola de formação de professores. In: FAZOLO, Eliane; CARVALHO, Maria Cristina; LEITE, Maria Isabel; KRAMER, Sonia. (Orgs.). Educação Infantil em curso. Rio de Janeiro: Ravil, 1997, p. 96-124.

DARDEAU, Tiago Cabral. Cultura digital - desafio para a escola. Jornal eletrônico Educação \& Imagem, v. 2, n. 13, maio 2009. Disponível em: <http://www.lab-eduimagem.pro.br/JORNAL/.>. Acesso em: 20 abr. 2010.

FERREIRA, Helenice Mirabelli Cassino; COUTO JUNIOR, Dilton R. Jogos Eletrônicos e Educação: um diálogo possível com a escola. Vertentes (São João Del-Rei), v. 33, p. 89-99, 2009.

JOBIM E SOUZA, Solange. O olho e a câmera: desafios para a educação na época da interatividade virtual. Revista Advir, Rio de Janeiro, n. 15, p. 75-81, set. 2002.

Ressignificando a psicologia do desenvolvimento: uma contribuição crítica à pesquisa da infância. In: KRAMER, Sonia; LEITE, Maria Isabel (Orgs.). Infância: fios e desafios da pesquisa. São Paulo: Papirus, 2007a, 9a Ed, p. 39-55. 
Dialogismo e alteridade na utilização da imagem técnica em pesquisa acadêmica: questões éticas e metodológicas. In: FREITAS, Maria Teresa (Org.); JOBIM e SOUZA, Solange (Org.); KRAMER, Sonia (Orgs.). Ciências humanas e pesquisa: leituras de Mikhail Bakhtin. São Paulo: Cortez, 2007b, 2a Ed, p. 77-94.

; KRAMER, Sonia. Experiência humana, história de vida e pesquisa: um estudo da narrativa, leitura e escrita dos professores. In: KRAMER, Sonia; JOBIM E SOUZA, Solange (Org.). História de professores: leitura, escrita e pesquisa em educação. São Paulo: Ática, 2003, p. 13-42.

KISHIMOTO, Tizuko M. O jogo, a criança e a educação. São Paulo: Vozes, 2002.

LEITE, Maria Isabel. O que falam de escola e saber as crianças da área rural? Um desafio da pesquisa no campo. In: KRAMER, Sonia; LEITE, Maria Isabel (Orgs.). Infância: fios e desafios da pesquisa. São Paulo: Papirus, 2007, 9a ed, p. 73-96.

LEMOS, André. Aspectos da Cibercultura: vida social nas redes telemáticas. In: PRADO, José Luiz Aidar (Org.). Crítica das práticas midiáticas: da sociedade de massa às ciberculturas. São Paulo: Hacker Editores, 2002, p. 112-129.

Cidade e mobilidade. Telefones celulares, funções pós-massivas e territórios informa-

cionais. Disponível em <http://www.intermidias.com/txt/ed9/cidade\%20e\%20mobilidade_andrelemos.pdf. >. Acesso em: 15 ago. 2009.

LÉVY, Pierre. Cibercultura. Tradução de Carlos Irineu da Costa. São Paulo: Editora 34, 1999. MACHADO, Arlindo. Regimes de imersão e modos de agenciamento. Trabalho apresentado no XXV Congresso Brasileiro de Ciências da Comunicação - Intercom. Anais... Congresso Brasileiro de Ciências da Comunicação - Intercom. Salvador/BA, 2002.

Arte e mídia: aproximações e distinções. Revista Eletrônica E-compós, v. 1, dez. 2004. Disponível em: <http://revcom2.portcom.intercom.org.br/index.php/galaxia/article/viewFile/1309/1079>. Acesso em: 30 out. 2007.

MARTINS, Daniele M.; COUTO JUNIOR, Dilton R. Jovens jogadores de videogames e produção de sentidos: contribuições para se pensar práticas educativas alteritárias. Trabalho apresentado na 30a ANPED. Anais... da 30a ANPED. Timbaúba: Espaço Livre, 2007, p. 1-6. (Publicado em CD-ROM).

NOGUEIRA, Letícia. Imagens da criança no computador. In: KRAMER, Sonia; LEITE, Maria Isabel (Orgs.). Infância e produção cultural. São Paulo: Papirus, 2007, 6a ed., p. 109-29. 
NÓVOA, António. Os professores na virada do milênio: do excesso dos discursos à pobreza das práticas. Educação e Pesquisa, São Paulo, v. 25, n. 1, p. 11-20, jun. 1999.

OROFINO, Maria Isabel. Educação intercultural, mídia e mediações: aportes das teorias latino-americanas da comunicação e consumo cultural. Disponível em: <http://www.ufsm.br/linguagem_e_ cidadania/02_02/MariaIsabelLC8.htm. >. Acesso em: 13 fev. 2006.

Mídias e mediação escolar: pedagogia dos meios, participação e visibilidade. São Paulo: Cortez, 2005.

OSWALD, Maria Luiza. A relação do jovem com a imagem: um desafio ao campo de investigação sobre a leitura. Trabalho apresentado na 30ª ANPED. Anais... da 30ª ANPED. Timbaúba: Espaço Livre, 2007, p. 1-15. (Publicado em CD-ROM).

RAMAL, Andrea Cecília. Ler e Escrever na Cultura Digital. Disponível em: < http://www.revistaconecta.com/destaque/edicao04.htm>. Acesso em: 9 mar. 2010.

SANTAELLA, Lucia. O papel do lúdico na aprendizagem. Revista Teias, v. 13, n. 30, p. 163-173, set./ dez. 2012.

Intersubjetividade nas redes digitais: repercussões na educação. In: PRIMO, Alex. (Org.). Interações em rede. Porto Alegre: Editora Sulina, 2013, p. 33-47.

A crítica das mídias na entrada do século 21. In: PRADO, José Luiz Aidar (Org.). Crítica das práticas midiáticas: da sociedade de massa às ciberculturas. São Paulo: Hacker Editores, 2002, p. 44-56.

A leitura fora do livro. Disponível em: <http://www.pucsp.br/pos/cos/epe/mostra/santaell. htm>. Acesso em: 3 maio 2008.

Navegar no ciberespaço: o perfil cognitivo do leitor imersivo. São Paulo: Paulus, 2004.

SIMÕES, Ana Paula Lima; COUTO JUNIOR, Dilton R. Das Mídias de Massa às Mídias Pós-Massivas: uma reflexão sobre o letramento na cibercultura. Trabalho apresentado no Congresso Internacional Cotidiano Diálogos Sobre Diálogos. Anais... do III Congresso Internacional Cotidiano Diálogos Sobre Diálogos. Rio de Janeiro: Editora Laboratório Educação e Imagem, 2010, p. 1-4. (Publicado em CD-ROM). 
Submetido para avaliação em 07 de outubro de 2010.

Aprovado para publicação em 01 de setembro de 2013.

Dilton Ribeiro do Couto Junior: Formado em Pedagogia pela Universidade do Estado do Rio de Janeiro (UERJ), com especialização em educação infantil pela Pontifícia Universidade Católica do Rio de Janeiro (PUC/Rio) e mestrado pelo Programa de Pós-Graduação em Educação da UERJ (ProPEd/UERJ) - Rio de Janeiro-RJ - Brasil. E-mail: junnior_2003@yahoo.com.br 